\title{
Criação de emojis: as invenções juvenis de Si em uma inspiração Sociopoética*
}

\begin{abstract}
RESUMO: O estudo objetivou analisar os sentidos autorrepresentativos juvenis impressos em emojis produzidos artisticamente por 13 jovens alunos de Ensino Médio do Instituto Federal do Piauí, Campus Valença do Piauí, durante a realização de uma oficina inspirada na metodologia Sociopoética e em respostas ao tema gerador $O E$ Eu. Os emojis são elementos comunicativos e anunciativos de representações dos sujeitos em funções discursivas e subjetivas em redes sociais, assim, firmam-se como elementos símbolos da juventude. Os pensamentos de vários teóricos justificam a escolha da produção de dados através da criação dos emojis por cada estudante, na intenção de despertar o potencial inventivo e sensível dos participantes da oficina. As criações dos emojis como invenções juvenis de Si com material de recorte, colagem, desenho e pintura em papel cartão foram analisadas intuitivamente e por uma leitura poética com olhares sensíveis. Constata-se, que do processo de produção simbólica dos emojis ao confronto da análise com aportes teóricos, os marcos delineadores da juventude não podem ser definidos com homogeneidade e singularidade, evidenciando a não existência de uma classificação pré-definida para a identidade jovem. Dessa forma, outros caminhos e conexões abrem-se para (re)interpretações dos multi/plurisentidos de suas identidades individuais, bem como, de suas categorias. Ainda, evidencia-se, as influências advindas dos diferentes modos representativos no ciberespaço, na produção identitária fora dele e vice-versa, corroborando as diversidades e diferenças nos modos de Ser juvenil.
\end{abstract}

Palavras-chave: Emojis. Cultura Digital. Juventudes. Identidades Juvenis. Sociopoética.
Douglas Pereira da Costa Universidade Federal do Piaú (UFPI)

Mestre em Educação (UNILOGOS) douglascosta.15@hotmail.com

* Uma versão mais enxuta desse artigo foi publicada nos Anais do III Encontro Internacional de Sociopoética e Abordagens Afins (Teresina/PI, 2018), disponível em: https://encontrosociopoetica. wixsite.com/encontrosociopoetica/ anais.

\section{Introdução}

Atualmente, as redes sociais virtuais são meios de comunicação e interação presentes no contexto social das juventudes. Dessa forma, os jovens constituem suas representações sociais e interativas no ciberespaço e, para isso, criam formas digitais, ciberculturais e inovadoras com o intuito de transparecer suas emoções nos ambientes midiáticos informacionais e tecnológicos.

Paiva (2016, p. 396) enuncia a linguagem dos emojis, uma forma acessível de comunicação entre atores em redes sociais, em que seu uso, pontua e complementa os sentidos das escritas nas mídias, "[...] ao mesmo tempo, fazendo emergir sentidos acrescidos de muitos outros significados, especialmente, de emoções". Explicitando maiores significados, Brito (2008, p. 19) aponta que "[...] os emoticons transmitem identidade e valores (cyber) culturais, ou seja, práticas, atitudes, modos de pensamento relacionados ao novo estilo de vida, que se refere ao universo cyber". 
Os relatos acima são resultantes dos efeitos da nova era digital. A ascensão explosiva da internet tem propiciado novas formas de configurações identitárias juvenis e novas maneiras de autorrepresentá-las. Nesse contexto, a "[...] era da internet, em que estão crescendo os Nativos Digitais, está proporcionando outra grande mudança no que significa construir e administrar a própria identidade". (PALFREY; GASSER, 2011, p. 29)

Diante disso, movida pelos princípios sociopoéticos e tendo em vista que a utilização desses recursos digitais são cada vez mais comuns no cotidiano da cibergeração, a presente pesquisa objetivou analisar os sentidos autorrepresentativos juvenis em emojis produzidos artisticamente por treze jovens alunos de Ensino Médio do Instituto Federal do Piauí, Campus Valença do Piauí, durante a realização de uma oficina inspirada na metodologia Sociopoética e em respostas ao tema gerador $\mathrm{O} \mathrm{Eu}$.

Dayrell (2003) considera difícil a missão de construir as definições do Ser jovem. No entanto, flexiona essa categoria em uma condição social plural constituída por critérios múltiplos "[...] para enfatizar a diversidade de modos de ser jovem existentes. Assim compreendida, torna-se necessário articular a noção de juventude à de sujeito social". (DAYRELL, 2003, p. 42) Então, quem melhor do que os próprios jovens para responder sobre quem são? Em especial, no contexto da cultura digital em que surge e se afirma "[...] a ideia de autorrepresentação: as pessoas querem se representar, e não mais ser representadas". (CANEVACCI, 2015, p. 16)

Realizada em 28 de novembro de 2017, a oficina buscou respostas sobre representações de Si juvenis nas criações dos estudantes participantes, que analisadas, serão subsídios para a compreensão dos sentidos autorrepresentativos das novas gerações. Para isso, o estudo segue teorizando emojis; posteriormente, relata sobre as fontes inspiradoras da metodologia, bem como, sobre o percurso investigativo; em seguida, a partir das invenções de si em conexão com as análises do pesquisador, apresenta as criações dos jovens e os resultados das análises descritivamente; e, finalizando, uma breve conclusão que abre espaço para novas vias de (re)interpretações. 


\section{Os emojis e emoctions: autorrepresentações juvenis em redes sociais}

Teoricamente, há diferença nas classificações dos termos emojis e emoctions. Tal distinção é explicada por conta de suas composições, segundo Moro (2016, p. 60), enquanto, os primeiros são representados por imagens gráficas, os segundos são constituídos por caracteres do próprio texto. No entanto, de forma breve, serão abordadas suas semelhanças, ou seja, nos sentidos enunciados por eles, até porque, há autores que não os distinguem, abordando-os com a mesma terminologia.

Para melhor compreensão dos emojis partimos dos princípios de pictogramas:

Os pictogramas são elementos visuais que, na contemporaneidade, compõem um sistema de sinalização e comunicação. Sua natureza figurativa e lúdica tem a capacidade de comunicar mensagens complexas. [...] O pictograma compõe um conjunto de símbolos gráficos ligados a objetos, representações e conceitos. [...] Possui também a função comunicativa de mediador de uma mensagem. (MORO, 2016, p. 53)

Concedendo aos emojis condições de pictogramas, compreende-se que, além de elementos comunicativos, são anunciativos de representações dos sujeitos em funções discursivas e subjetivas: na substituição de palavras, nas expressões e ênfases emotivas, na indicação de afeto e alocuções irônicas (PAIVA, 2016, p. 393-395)

Decerto, as conexões em redes sociais, concedidas ciberculturalmente, acabam por nortear muito dos comportamentos humanos e suas identidades nos espaços de convivência física e pessoal. Assim sendo, a significação dos emojis é feita por meio dos princípios culturais: "[...] traduzindo imagens com as percepções de seu povo, de seus preceitos pessoais, criando novas significações de imagens". (MORO, 2016, p. 64) No âmbito dessa interatividade cultural, Palfrey e Gasser (2011, p. 29) afirmam que, para os nascidos nessa era, "[...] o ambiente digital é simplesmente uma extensão do físico".

Sob a ótica da cultura digital, a autorrepresentação é autônoma e os emojis enquadram-se como meios tecnológicos utilizados para representar a Si e aos modos de Ser juvenis.

A cultura digital modifica a 'divisão comunicacional do trabalho' [...] entre quem narra e quem é narrado. Surge então a ideia de

revista entreideias, Salvador, v. 9, n. 3, p. 129-149, set./dez. 2020 
(1) Doutora em Educação.

Professora do Programa de Pós-Graduação em Educação

da Universidade Federal do Piauí (UFPI). Coordenadora do Observatório das Juventudes e Violências na Escola - OBJUVE (Núcleo de Estudos da UFPI). Pesquisadora de temas relacionados às juventudes $e$ práticas educativas, tendo a Sociopoética como principal metodologia de pesquisa. autorrepresentação: as pessoas querem se representar, e não mais ser representadas. E, de qualquer lugar do mundo, elas têm os meios tecnológicos e condições culturais para fazer isso, para nunca mais conceder a um terceiro o direito de representá-las. (CANEVACCI, 2015, p. 16, grifo do autor)

Dentre a juventude, é comum a adesão e apropriação dos emojis nos discursos enunciativos de Si e de sentidos subjetivos, sejam em diálogos e em navegações pelo espaço virtual ou em produções manuais escritas e artísticas. Brito (2008, p. 12-13) explicita a forma como as publicidades destinadas ao público jovem têm feito uso desses signos na intenção de assinalar seus produtos como pertinentes a juventude contemporânea, tais como: preservativos, biscoitos, batatas fritas, joias e acessórios. Dessa forma, depreende-se desses contextos que os emojis são elementos símbolos dos nativos digitais.

\section{A inspiração sociopoética como metodologia sensível e inventiva de si}

Durante as trajetórias formativas do pesquisador deste estudo, foi inspirador o contato acadêmico com pesquisadoras sociopoéticas, tal como a professora Dra. Shara Jane Holanda Costa Adad ${ }^{1}$. A partir dos relatos sobre suas experiências no universo investigativo por meio da metodologia Sociopoética e suas técnicas, desencadeou-se o desejo de deslizar por trajetos semelhantes. Tal contexto motivou o desenvolvimento de uma oficina inspirada na Sociopoética com treze jovens alunos de Ensino Médio do Instituto Federal do Piauí, Campus de Valença do Piauí, como parte metodológica e analítica de uma pesquisa de mestrado sobre a subjetividade jovem expressa na rede social Instagram.

A Sociopoética é uma metodologia de pesquisa que favorece a criação de conceitos desterritorializados, "[...] a expressão Sociopoética surge de um neologismo que une o latim socius - aquilo que é coletivo -, ao grego poiésis, que significa criação. Desse modo, o termo designa a construção coletiva do conhecimento". (SANTOS, 2013, p. 35) Conforme o seu criador, o filósofo e pedagogo francês Jacques Gauthier, a utilização e aplicação da referida metodologia é norteada por cinco princípios:

a constituição de um grupo-pesquisador autor coletivo e cooperativo da pesquisa, sendo os acadêmicos os facilitadores da 
mesma; a valorização das culturas dominadas e de resistência na interpretação, e até, na criação dos dados; a mobilização de todas as capacidades cognitivas do ser humano, racionais críticas, míticas, sensíveis, intuitivas, emocionais, imaginárias, gestuais e espirituais; o uso de técnicas artísticas de pesquisa para favorecer essa integração cognitiva; enfim, a responsabilidade sociopolítica, ética, cognitiva e espiritual do grupopesquisador em todos os momentos da pesquisa (o que inclui seus efeitos pós-pesquisa). (GAUTHIER, 2014, p. 850, grifos nossos)

Nesse sentido, dizemos que a oficina é inspirada na Sociopoética pelo fato de seguir os princípios supracitados, apesar de não obedecer a todos os procedimentos e etapas de análises que a metodologia propõe através de seus teóricos. Todavia, a inspiração metodológica ganha vigor ao se deparar com tais princípios e orientações, pois vem a coincidir com a intencionalidade do estudo de buscar conhecer sobre as autorrepresentações juvenis.

Oportuniza-se a esses sujeitos, por meio de suas próprias produções, transformarem-se nos autores dos conhecimentos construídos sobre Si e suas categorias, de forma não mecanizada e nem em discursos padronizados, mas subjetiva, lúdica e artisticamente. Nessa perspectiva, a autorrepresentação denota que o pesquisador não pode "[...] mais representar a cultura dos bororos e xavantes, da periferia de São Paulo ou da juventude on-line, porque tanto os jovens indígenas quando os jovens metropolitanos ou os cibernautas afirmam seus direitos e desejos de representar a si mesmos" (CANEVACCI, 2015, p. 17).

O percurso investigativo foi realizado entre 02 de novembro e 16 de dezembro de 2017. A primeira etapa, desenvolvida em novembro, diz respeito ao planejamento geral, fundamentação teórico-metodológica das técnicas e atividades a serem utilizadas. Nesse período, solicitou-se à gestão administrativa do Instituto Federal do Piauí, Campus Valença do Piauí, autorização para realização do estudo com alunos do Ensino Médio da referida instituição, concedida por assinatura do Diretor-Geral do Campus em carta de anuência.

O primeiro contato com os estudantes participantes da pesquisa foi realizado o no dia 24 de novembro, o momento de apresentar o objetivo da pesquisa e convidá-los para vivenciarem a oficina. Sendo a participação condicionada aos seguintes critérios: possuir 
(2) O roteiro foi adaptado de um texto disponível no livro Juventudes, Cultura de Paz e Subjetividades, no capítulo Os corpos-bichos dos estudantes como mecanismo de fuga às identidades fixas: uma oficina Sociopoética, de autoria de Shara Jane Holanda Costa Adad e Marta Gama. (ADAD; GAMA, p. 161) redes sociais, ser jovem e manifestar interesse voluntariamente. $\mathrm{Na}$ oportunidade, foram explicitados os procedimentos éticos da investigação e encaminhado o Termo de Consentimento Livre e Esclarecido (TCLE) aos responsáveis pelos jovens.

A execução da oficina configura-se como a segunda etapa, ocorreu no dia 28 de novembro, em sessão única e com duração de $2 \mathrm{~h}$, em uma sala de aula da referida instituição escolar. Teve como objetivo conhecer as autorrepresentações juvenis produzidas de forma coletiva, artística e não hierarquizada entre pesquisador e objeto de estudo em uma inspiração Sociopoética. Contou com a participação de treze jovens (cinco alunos e oito alunas) compreendidos entre 15 e 17 anos de idade. Ressalta-se que, como público-alvo da oficina, os estudantes compõem o grupo-pesquisador, como é denominado o coletivo participante da pesquisa em Sociopoética.

Sobre as técnicas, procedimentos e dispositivos aplicados na oficina, inicialmente, apresentou-se o objetivo da sessão aos copesquisadores, assim são nomeados individualmente os participantes de pesquisas na Sociopoética, devido a tornarem-se cooperadores da pesquisa. A partir disso, houve uma rápida negociação para o tema gerador da oficina, definido pelo grupo-pesquisador como $\mathrm{O} E \mathrm{E}$.

Após isso, buscou-se proporcionar o relaxamento dos estudantes, a sala espaçosa foi um palco para que os jovens pudessem dançar livremente ao som de músicas que iam sendo alteradas pelo pesquisador-facilitador. Foi solicitado que sentissem o corpo, dançassem e pulassem ao ritmo da música e ao gosto próprio, sozinhos, em duplas, trios ou como achassem melhor. A escolha dessa técnica, parte do que preconiza Gauthier (2014, p. 850) sobre "[...] incluir a dança - cada um dançando o quê e como seu corpo sente e pensa - nas técnicas de relaxamento favorecendo a produção dos dados".

Ao som da última música (calma, relaxante e instrumental), os copesquisadores foram conduzidos a sentarem-se no chão para darem continuidade ao momento de relaxamento, através do "[...] dispositivo de brincar-de-bichos. [...] onde cada copesquisador brinca de sentir e atuar como um animal". (GAUTHIER, 2014, p. 850) De olhos fechados, os jovens ouviram atentamente a leitura de um roteiro ${ }^{2}$, em que assumiriam uma personagem, um animal de sua escolha e teriam contato com a natureza no decorrer de uma viagem, na qual vivenciariam desafios (sair de um buraco, escalar uma montanha e atravessar um rio), por fim, deparar-se-iam com 
um espelho e o roteiro encerrava com o questionamento: o que é o bicho do Eu?

De forma alguma, o corpo poderia ser deixado de lado nesse itinerário investigativo, a pesquisa tem que ser com o corpo todo. Segundo a Adad (2014, p. 48), "[...] fazer Sociopoética é não separar a cabeça do resto do corpo. [...] O corpo produz conhecimento". Com isso, entende-se que o corpo por completo é pensante e produtor. Por essa razão, todo o processo de esgotamento com a música, relaxamento com o texto e os demais procedimentos no decorrer da oficina com o grupo-pesquisador. A partir disso, a potencialidade corporal é ativada para o momento das criações.

Em sequência, já com os jovens de olhos abertos, foi requerido aos copesquisadores que se expressassem plasticamente respondendo ao questionamento do roteiro. Para isso, os estudantes receberam massas de modelar. No entanto, essa pesquisa não aborda essa produção de dados, porém, considerou-se de grande valia relatar os precedentes ocorridos na oficina antes das invenções juvenis que servirão de análise para esse estudo.

Depois das expressões orais abertas sobre as produções com massas de modelar e a análise do grupo-pesquisador sobre o produzido. O facilitador solicitou aos copesquisadores que criassem - com material de recorte, colagem, desenho e pintura em papel cartão - um emoji de "autoria própria" ou um já existente nas redes sociais que fosse capaz de representá-los, de responder ao questionamento do roteiro de relaxamento e pertinente ao tema gerador da oficina. Ao final, colaram suas criações em um crachá confeccionado pelo pesquisador, do tamanho da metade de uma folha de papel A4, nomearam a produção para ciência apenas do pesquisador-facilitador e discorreram livremente sobre suas invenções. Enfatizamos que devido ao sigilo ético quanto a não identificação do grupo-pesquisador, as criações de emojis não foram por ele explicadas e analisadas conjuntamente, apenas entregues ao facilitador com a identificação real de cada jovem, o nome dado ao emoji e as descrições de suas produções. Pois, esses seriam seus pseudônimos no decorrer de toda a pesquisa de mestrado.

As criações de emojis e as anotações dos estudantes deram origem aos dados analisados neste estudo. Em um levantamento bibliográfico, não foi encontrado registro de pesquisas sociopoéticas com técnicas de criação de emojis pelo grupo-pesquisador. Para Gauthier (2015, p. 82): "As técnicas de inspiração artística são 
múltiplas e cada facilitador pode inventar técnicas que correspondem ao seu gosto e saber-fazer". É nesse quesito que reside o aspecto inventivo da inspiração na Sociopoética, ou seja, na liberdade de inventar conforme as criatividades e habilidades do pesquisador. Por outro lado, a condição sensível é percebida no estímulo de produções através da arte, que percorre os sentidos do estranhamento passando pela criação até chegar na construção, desconstrução e reconstrução de conceitos.

Pesquisar com arte, significa estimular a criatividade, a
sensibilidade e a capacidade do grupo-pesquisador, levando-o a
criar outras ideias e conceitos sobre a vida e os problemas que o
mobiliza, de forma lúdica, imaginativa e poética. A arte provoca
o deslocamento, proporciona o estranhamento e possibilita
outras formas de pensar o tema-gerador. (SANTOS, 2013, p. 57)

Os posicionamentos supracitados e as concepções teóricas e metodológicas apresentadas justificam a escolha da produção de dados através da criação do emoji por cada copesquisador. Teve-se como intenção despertar o potencial inventivo e sensível de cada um, pois além de ser um elemento emergente na cultura digital vivenciada pelos jovens do estudo (afirmaram ter acesso diário às redes sociais de, no mínimo, 3 horas), o emoji compõe um sistema de comunicação figurativo e lúdico com capacidade de transmitir mensagens complexas e que "[...] em muitos casos, pode quebrar obstáculos linguísticos entre diferentes culturas e níveis de conhecimento". (MORO, 2016, p. 53) Assim, acredita-se que os obstáculos linguísticos da expressão discursiva entre copesquisadores e pesquisador-facilitador tenham sido quebrados durante a produção artística e suas análises.

Apostamos na capacidade das técnicas escolhida de "[...] favorecer a leitura poética das pessoas". (CANEVACCI, 2009, p. 19) Isso, nos possibilita a sensibilização do olhar e ver novas formas de colocar em ação esse verbo no fazer da pesquisa. Em suma, é reinventar novos olhares, pois somos imbuídos a abri-los, principalmente, na emergência dos elementos e vivências ciberculturais da juventude, a exemplo, dos emojis.

Treinar a olhar e se olhar, olhar-se. Por que não há nada de natural em olhar. O olhar é sempre culturalmente determinado. Então que olhar seja culturalmente determinado significa que agora, no contexto atual, a coisa mais significativa, seja 
didaticamente, seja fazendo pesquisa, é aprender, desenvolver, modificar, inventar, formas novas de olhar. [...] falando de internet, a relação entre olho, tela, mão, mouse, cérebro, corpo, é muito mais interativa do que se poderia imaginar. (CANEVACCI, 2009, p. 14, grifo do autor)

Para finalizar a oficina, fizemos uma roda de embalo de mãos dadas e uma breve avaliação da experiência vivenciada em palavra única enunciada por cada um, das quais, algumas mencionadas foram: conhecimento, legal, "top", "massa", excelente e "show de bola". Por fim, os agradecimentos do pesquisador-facilitador encerrados com a \#gratidão (lê-se: hashtag gratidão).

A terceira e última etapa do percurso metodológico consistiu na análise dos emojis produzidos pelos copesquisadores e foi efetivada pelo pesquisador-facilitador entre os dias 28 de novembro e 16 de dezembro. As análises dos dados na abordagem sociopoética não são tarefas fáceis, exigem intuição, confiança, responsabilidade e um trabalho analítico em princípios sociopoéticos, tal como define Gauthier (2015, p. 83):

Em casa, tranquilamente, o facilitador estuda o conjunto dos dados e tenta apontar as regularidades e divergências que existem no grupo-pesquisador pensado como sendo um cérebro coletivo, um filósofo com ideias em conflito, divergência ou convergência, desdobramento ou isolamento etc. Essa é a tarefa mais difícil.

Além disso, em Sociopoética, depois dos dados produzidos e transcritos, o pesquisador realiza as seguintes análises:

A análise classificatória diz respeito às oposições (por exemplo, as dicotomias), alternativas e escolhas; a transversal é considerada por Jacques Gauthier uma não análise, porque destaca as ligações, as ambiguidades e as convergências; a análise filosófica faz referência às teorias escolhidas pelo facilitador, segundo suas inclinações, pois na Sociopoética temos a liberdade de escolher nossas próprias abordagens. Isto é, desde que não se sobreponham aos conceitos e confetos criados pelos copesquisadores. (ADAD, 2011, p. 255, grifo do autor)

Todavia, neste estudo, as análises não foram realizadas separadamente. Nesse contexto, recaiu sobre o pesquisador a incumbência de analisar todas as produções nos diversos sentidos teorizados. A 
partir das observações dos emojis e suas descrições, dos diálogos tecidos no decorrer da oficina e do contexto cultural, as produções foram analisadas intuitivamente e por uma leitura poética com olhares sensíveis.

Primeiramente, buscou-se perceber as particularidades de cada emoji, de seus nomes e das respectivas descrições transcritas pelos jovens. Em seguida, destacou-se semelhanças e divergências entre os sentidos percebidos nas criações. Em terceiro plano, observou-se os aspectos plásticos/estéticos das produções (traços dos desenhos, cortes, colagens, pinturas e semelhantes). Nesse momento, "O objetivo é descobrir, mediante leitura intuitiva, o que os próprios desenhos/figuras [...] nos comunicam". (PETIT, 2014, p. 36)

Por fim, foram correlacionadas as percepções obtidas pelo pesquisador durante as análises e, em uma abordagem filosófica, postas em face a estudos teóricos sobre as temáticas da pesquisa. Dessa forma, os resultados são apresentados descritivamente e sintetizados em um poema de autoria do pesquisador-facilitador com base no conhecimento coletivo produzido pelo grupo-pesquisador, configurando-se em uma análise surreal. "Esta análise consiste em brincar, em festejar, em subverter a estrutura do pensamento do grupo, criando uma outra lógica. Ela é, portanto, nada convencional". (ADAD, 2011, p. 255)

\section{A conexão entre as criações dos emojis e as análises do pesquisador}

Vejamos abaixo as criações de emojis do grupo-pesquisador, lembrando que foram produzidos em respostas ao tema gerador $O$ Eu, o que fazem deles expressões de autorrepresentações juvenis dos estudantes participantes da oficina.

Figura 1 - Criação dos Emojis

A

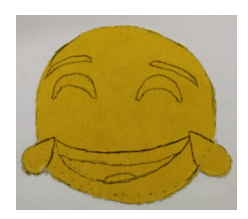

B

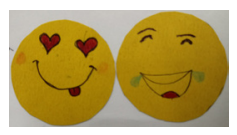

C

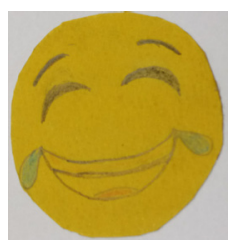



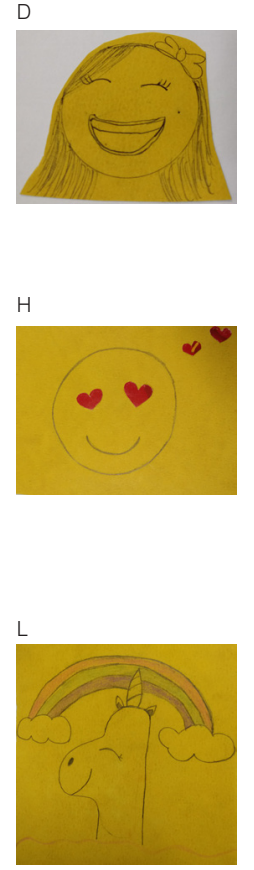
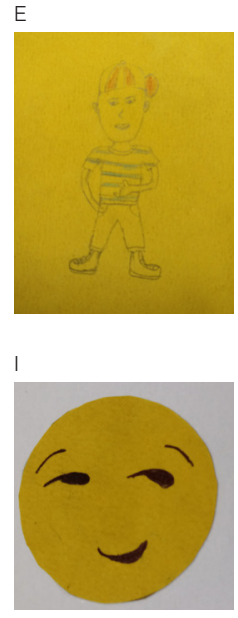

M

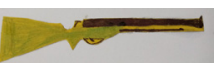

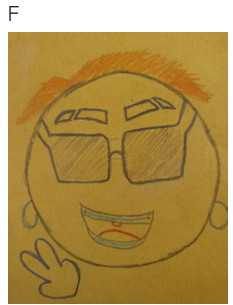
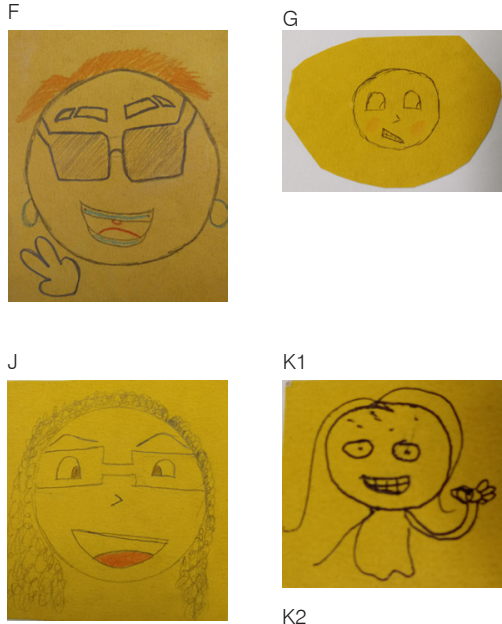

$\mathrm{K} 2$

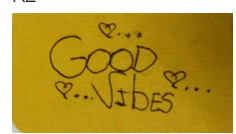

Eticamente, em pesquisa há uma preocupação com a escolha de pseudônimos para os sujeitos anônimos. No entanto, dificilmente desenvolve-se uma análise sobre as razões que induzem os participantes a essa escolha, seus significados e sentidos. Mas isso não pode passar desapercebido numa pesquisa sobre autorrepresentação, pois as criações de pseudônimos "[...] favorecem o pensamento livre, evidenciando o território, a desterritorialização e a reterritorialização". (CASTRO, 2014, p. 223) Nesse processo, os jovens foram capazes de pensar $O \mathrm{Eu}$ de uma forma nova, em um movimento de ida e vinda na ocupação corporal nos espaços físicos, subjetivos, intuitivos e virtuais.

Conforme as indicações alfabéticas, os copesquisadores nomearam as criações de Si: a) Sorriso; b) Apaixonado Sorridente; c) Carinha de Riso; d) Gaiata; e) Garoto de Boné; f) Doidinha; g) Desconfitímido; h) Olhos de Coração; i) Teddy e Eu; j) Cachinhos Dourados; k) Good Vibes; 1) Unicórnios; e, m) Atirador.

Diante disso, percebe-se que os copesquisadores transferem características pessoais para suas produções. Desconfitímido é a junção de desconfiado + tímido, Gaiata e a largura do riso no emoji produzido inferem a ideia de alguém brincalhona e sorridente, os 
cabelos cacheados sinalizam a denominação de Cachinhos Dourados, enquanto, a combinação entre a produções artísticas e as nomeações de Doidinha e Garoto de Boné evocam um estilo despojado.

Existe a Emojipédia, enciclopédia virtual para nomes e significados de emojis. Porém, no estudo, destaca-se a criatividade juvenil em suas titulações, deixando suas marcas e particularidades, impregnando nelas sentidos próprios. Isso aponta para as metáforas, sobre as quais Gauthier (2004, p. 131) diz, "[...] a metáfora visa a algo que não está dado, que não está presente, ela dá vida a um produto da imaginação". Coincidentemente, essa é uma das funções figurativas dos emojis. Os jovens utilizaram metáforas subjetivas no conjunto de suas criações para darem vidas às representações imaginárias de Si.

Apesar de algumas criações se assemelharem às famosas "carinhas" de aplicativos de redes sociais, os copesquisadores produziram novas "interfaces" para esses elementos significativos e complexos em sentidos. Com isso, houve quem, conforme sua subjetividade, (re)inventasse um emoji representativo de si. A geração digital é caracterizada pelo prazer da personalização, que faz isso ao seu gosto e movida por sensibilidades. "A inovação pertinente à geração de nativos digitais traspassa por uma subjetividade criativa". (COSTA; VIEIRA, 2019, p. 20)

Outro aspecto observado é a predominância de expressões faciais, fato recorrente na aplicação de fotografias nos perfis de aplicativos de redes sociais, assim como, os sorrisos largos e demonstrações de alegria. Em alguns outros, há a presença de manifestações afetivas - Olhos de Coração - e de paixões, Teddy e Eu faz menção ao compromisso de namoro que a jovem possuía, Apaixonado Sorridente, com a mesma intenção de Teddy e Eu, desenha dois emojis lado a lado. Os jovens são seres relacionais e, como sujeitos sociais, vivem nessa fase da vida, "[...] um momento cujo núcleo central é constituído de mudanças do corpo, dos afetos, das referências sociais e relacionais. Um momento no qual se vive de forma mais intensa um conjunto de transformações que vão estar presentes, de algum modo, ao longo da vida". (DAYRELL, 2003, p. 42)

De uma forma ou de outra, as emoções estão vinculas as invenções de si veiculadas pelos emojis. De modo que Desconfitímido preocupa-se em desenhar o sorriso, olhar de lado e em aplicar uma pintura rosada na bochecha, sinalizando mais uma vez a 
desconfiança e timidez. Imbuir emoções em autorrepresentações é uma forma coletiva e conectada de "[...] construir uma representação na qual estão colocadas também as nossas personalidades, experiências, emoções e valores". (CANEVACCI, 2015, p. 17)

O objeto retratado nas produções é o de Atirador, justificado pela luta diária do jovem para prosseguir na busca de seus sonhos e anseios. Doidinha, em anotações, considera-se "doidinha" por possuir uma personalidade que se equilibra/se desequilibra entre brincadeiras e seriedades do cotidiano. Semelhantemente, Unicórnios, uma figura mitológica e cheia de magia, é comumente associado pela juventude ao fato da crença em dias melhores, felizes e sem preconceitos, ou como a copesquisadora diz, "é crer na força e no amor para superar obstáculos e nunca desistir". Esses signos enunciativos, relacionam-se ao tempo da juventude, que mantém o foco no presente.

O tempo da juventude, para eles, localiza-se no aqui e agora, imersos que estão no presente. E um presente vivido no que ele pode oferecer de diversão, de prazer, de encontros e de trocas afetivas, mas também de angústias e incertezas diante da luta da sobrevivência, que se resolve a cada dia. Não significa que sejam alienados ou passivos, que não nutram sonhos e desejos. (DAYRELL, 2003, p. 49)

Percebe-se que os jovens vivem, prioritariamente, o tempo presente. Mas também sonham e projetam futuros com base em sonhos e desejos. Todavia, mesmo que inconscientes, percebe-se a aspiração de manter os traços infantis: o lacinho no cabelo de Gaiata; o colorido arco-íris e nuvens, além da simbologia infanto-juvenil de Unicórnios; e, conforme em destaque, "Garoto" de Boné.

Sobre essa composição autorrepresentativa subjetiva, Canevacci (2009, p. 9) desenvolve o conceito de multivíduos, referente à "[...] multiplicidade de eus no corpo subjetivo", que se intensifica com a possibilidade de conexões simultâneas com/entre/em espaços-tempos-pessoas diferentes. Os marcos característicos dessa identidade são a fluidez e a pluralização, que colocam as formas tradicionais em crises. Em observância ao conjunto de enunciado das artes produzidas e do contexto teórico, esses sujeitos rompem com os paradigmas conceituais e estéticos sobre o modo de Ser jovem.

É perceptível o surgimento de uma nova linguagem com a internet e frutos dos discursos no ciberespaço, "[...] a linguagem 
digital. Este novo processo de construção discursiva da linguagem criou novos códigos e um novo vocabulário" (BRITO, 2008, p. 6). Tal como Good Vibes, que traduzido da língua inglesa significa boas energias, resulta da influência das redes sociais virtuais no discurso e na formação identitária juvenil, pois as juventudes adotam o idioma constantemente em publicações. Nas anotações descritivas sobre as criações dos jovens foi identificada a expressão "vida loka", correlacionada à excitação do risco, ao destemor e à virilidade.

\begin{abstract}
Por que é que alguns jovens se envolvem em condutas de risco? Porque elas possibilitam pôr em acção dotes de ousadia e de habilidade, logrando uma efectividade da qual carecem em situações rotineiras. A excitação do risco alimenta-se de uma 'coragem de existir' - coragem que se demonstra na exposição ao risco e na submissão à qualidade de prova. O que conta, para alguns jovens, parece ser a possibilidade que têm de, numa fase de vida em que a maioria dos discursos dominantes lhes outorgam um vazio de poder, se entregarem a actividades cuja visibilidade é incrementada pelos riscos (reais ou pressentidos) que lhes aparecem associados. (PAIS, 2005, p. 63)
\end{abstract}

Durante a leitura intuitiva (análise) dos aspectos plásticos das produções, relativos aos recursos artísticos utilizados pelos jovens em suas criações, percebeu-se que os jovens alunos preferiram desenhar e pouco colorir, que recorte e colagem foram utilizados apenas por um copesquisador ao sobrepor os olhos em formato de coração sobre sua criação. E, ao tempo em que customizam e detalham as criações, eles também aderem à praticidade.

É nesse momento que vemos todas as potencialidades do corpo. "Na Sociopoética, corpos se misturam, fundem-se, tornam-se flexíveis, conseguem escapar da armadura, do lastro organismo-disciplinado-rígido-submisso e se potencializam, tecendo devires, intensificando a vida, problematizando-a". (ADAD, 2001 apud ADAD, 2014, p. 49-50) Melhor ainda, flexionamos o corpo para o plural corpos, pois "[...] ele não é único, é uma multiplicidade em fusão". (ADAD, 2014, p. 48)

Assim, enfatizamos a presença do corpo virtual do grupo-pesquisador, esse corpo é subjetivo e imaginário, mas que nas flexões, fusões e multiplicidades de corpos, ganhou forma, assim, potencializando a produção corporal dos emojis em sentidos e significados em respostas aos questionamentos sobre a autorrepresentação juvenil - O Eu. Foi no processo de territorialização-desterritorialização-reterritorialização 
do corpo virtual que transitou pelo ciberespaço, o que segundo Martins e Adad (2014), culminou em um corpo cibercultural.

[...] pois o corpo pode ser sim virtual. Também, através de linguagens que manifestam desejos, vontades e prazeres dos corpos juvenis que respondem às questões do ciberespaço como: quem sou eu? E o que você está pensando agora? Portanto, podemos perceber que são muitas as representações existentes nos espaços das redes, pois estas se manifestam através de códigos típicos da comunicação nestes espaços, como por exemplo, "carinhas" para demonstrar emoções como tristezas, alegrias, gestos corporais. (MARTINS; ADAD, 2014, p. 93)

Os emojis criados pelos estudantes manifestaram a representação identitária juvenil do grupo-pesquisador entre traços, rabiscos, pontos, linhas, arcos, desenhos, recortes, colagens, pinturas, escritas, apagões, sempre (re)fazendo, (re)sentindo, (re)criando, (re) produzindo e, aqui, unem-se em corpos. E, esse encontro pode ser determinado como "[...] Subjetividades entremeadas com pontos e linhas que se conectam formando uma rede em que o outro e a vida são as principais potências a serem sentidas". (ADAD, 2014, p. 51)

A criação inventiva de si juvenil, em forma de um elemento do corpo virtual (emoji), exigiu dos copesquisadores um exercício sobre olhar-se, ver-se e, assim, "[...] Fazer-se olho, fazer-se ver, que significa desenvolver uma sensibilização do olhar, dos olhares, de se olhar e de olhar, que é um treino, um exercício. Treinar-se a desenvolver uma sensibilidade sensorial e conceitual, baseada num corpo cheio de olhos". (CANEVACCI, 2009, p. 19, grifo do autor)

Os olhares se traduzem em todos os sentidos possíveis da capacidade humana. Assim, o pesquisador teve a necessidade de aguçar o corpo cheio de olhos e ativar zonas subjetivas sensíveis que buscassem analisar os pontos e linhas que, ao interligam-se (ou não), formassem não um conceito, mas viabilizassem compreensões acerca das autorrepresentações juvenis contemporâneas, contemplando-as em homogeneidades e heterogeneidades.

Nenhum ser humano é exatamente igual a outro - e isso se aplica tanto aos jovens quanto aos velhos. Contudo, é possível notar que, em determinadas categorias de seres humanos, algumas características ou atributos tendem a aparecer com maior frequência que em outras. É essa 'condensação relativa' de traços característicos que nos permite falar, em 
primeiro lugar, em 'categorias', sejam elas nações, classes, gêneros ou gerações. Ao fazê-lo, ignoramos temporariamente a multiplicidade de características que faz de cada um de seus integrantes uma entidade única e irrepetível, diferente de todas as outras, um ser que se destaca de todos os demais membros da 'mesma categoria'. (BAUMAN, 2011, p. 58, grifo do autor)

Assim, não podemos cometer o erro de reduzir as categorias juvenis a um conceito único e fechado. Em função disso, os olhares do pesquisador em conexão com os olhares do grupo criaram um poema considerado surreal em um jogo de palavras figurativas em torno dos múltiplos significados da palavra sentido. Recorrendo ao ponto conclusivo de que a identidade autorrepresentativa juvenil é múltipla e plural em sentidos, tanto no que tange aos sujeitos sociais em suas particularidades, quanto na interpretação de categorias dessa geração.

Mesmo sendo de autoria escrita do facilitador, reforçamos a pluralidade criativa na conjugação verbal pelo motivo de ser um poema resultante das subjetividades, sensibilidades, corpos potenciais, vidas, sentidos, olhos e olhares na conectividade entre os jovens alunos e o pesquisador. Ou seja, o emoji abaixo poetizado faz referência às autorrepresentações juvenis construídas coletivamente pelo grupo-pesquisador em inspirações sociopoéticas, constituindo-se em conhecimento sobre as juventudes e os modos de Ser jovem.

\section{Emoji tem sentidos?}

Emoji fala? Emoji ouve?

Emoji sente? Emoji ver?

Emoji toca?

Emoji tem sentidos?

- Depende!

Em traços e rabiscos,

Emoji até sorrir...

Seus sentidos são cheios de devir.

Fala com as pontas dos dedos,

Ouve com olhos.

E que olhos grandes! Outros pequenos!

Há os apaixonados e os desconfiados.

Emoji toca com a emoção,

Tem "vida loka" e curtição,

Equilibra em corda bamba

Para na vida bamba não desequilibrar. 
O sentido do emoji está em sentir...

Sentir afeto, esperança,

Amor e emoção.

Ou seria em transferir?

Emoji fala, ouve, sente, ver e

Toca com o corpo todo

Ou com todos os corpos.

Assim, senti o outro,

Senti a vida com sentido.

Emoji tem múltiplos sentidos,

Só depende de quem é tocado.

E, por fim, por aqui,

Emoji tem sentidos, sim!

\section{Conclusões: olhares que contemplam multi/plurisentidos juvenis}

Constata-se que a conexão entre os procedimentos metodológicos inventivos de si inspirados na Sociopoética e emergidos da cibercultura com a simbologia e linguagem dos emojis criados pelo grupo-pesquisador foi capaz de quebrar barreiras comunicativas com os jovens, favorecer a subjetividade e desconstruir (pré)conceitos, firmando, assim, a técnica utilizada como inventiva e sensível em pesquisas com sujeitos da geração digital.

Do processo de produção simbólica dos emojis ao confronto das análises com aportes teóricos, elucida-se que os marcos autorrepresentativos da juventude não podem ser definidos com homogeneidade e singularidade, evidenciando a não existência de uma classificação pré-definida para a identidade jovem. O ato da criação artística é transferidor de subjetividades. Assim, induzir o olhar juvenil para Si e fomentá-los a produzir conhecimentos sobre suas categorias é permitir que, por meio de dispositivos inventivos e sensíveis, sejam parte da construção teórica-científica de Si e do Ser jovem.

Certamente, muitos outros subsídios sobre as autorrepresentações juvenis poderiam ser extraídos das criações de emojis. Dessa forma, outros caminhos e conexões se abrem para (re)interpretações dos multi/plurisentidos de suas identidades individuais, bem como, de suas categorias. O fato desses sujeitos assumirem variadas formas corporais em tempos-espaços simultâneos contribui para a amplitude de vias interpretativas. 
Nos múltiplos olhares do corpo e de todos os corpos, especificamente sobre o corpo virtual, sente-se, toca-se, ouve-se, fala-se e contempla-se a cibercultura como presente e influente na vida e nos sentidos da juventude. Nesse campo, evidencia-se as influências das diferentes formas representativas advindas do ciberespaço na produção identitária fora dele e vice-versa, corroborando as diversidades e diferenças em seus modos de Ser jovem.

Portanto, fica em aberto uma reflexão sugestiva aos pesquisadores, acadêmicos e, em especial, aos educadores, sobre a necessidade de reinventar novas formas de olhar, olhar para si e para a cibergeração, rompendo com o superficial e com a visibilidade que insiste em padronizar os comportamentos dos sujeitos e, assim, compreender as multiplicidades e pluralidades juvenis.

\title{
Creating emojis: youthful inventions of himself in a sociopoetic inspiration
}

\begin{abstract}
The study aimed to analyze the representative meanings of youth identities printed on emojis artistically produced by high school students from a federal public school institution in Valença do Piauí during the realization of a workshop inspired by Sociopoetics and in responses to the generating theme The self. Emojis are communicative and advertising elements of representations of subjects in discursive and subjective functions in social networks, thus, they establish themselves as elements symbols of youth. The several theoretical thoughts justify the choice of data production through the creation of emojis by each co-researcher, with the intention of awakening their inventive and sensitive potential. The creations of the emojis as youthful inventions of themselves with cutting, collage, drawing and painting material on cardboard were analyzed intuitively and through a poetic reading with sensitive eyes. It appears that, from the symbolic production process of the emojis to the confrontation of the analysis with theoretical contributions, the outlines of youth cannot be defined with homogeneity and uniqueness, showing the absence of a predefined classification for youth identity. In this way, other paths and connections open up for interpretations of the multi / plurisense of their individual identities, as well as, of their categories. Still, it is evident, the influences arising from the different representative modes in cyberspace in the identity production outside of it and vice versa, corroborating with the diversities and differences in the ways of being youthful.
\end{abstract}

Keywords: Emojis. Digital Culture. Youths. Youth Identities. Sociopoetics.

\section{Creación de emojis: inventos juveniles de sí mismos en una inspiración sociopoética}

RESUMEN:El estudio tuvo como objetivo analizar los significados representativos de las identidades juveniles impresas en emojis producidos artísticamente por estudiantes de secundaria de una institución federal de escuelas públicas en Valença do Piauí durante la realización de un taller inspirado 
en la sociopoética y en respuestas al tema generador El yo. Los emojis son elementos comunicativos y publicitarios de representaciones de sujetos en funciones discursivas y subjetivas en las redes sociales, por lo que se establecen como símbolos de elementos de la juventud. Los pensamientos de varios teóricos justifican la elección de la producción de datos. mediante la creación de emojis por cada coinvestigador, con la intención de despertarsu potencial inventivo y sensible. Las creaciones de los emojis como invenciones juveniles de sí mismos con material de corte, collage, dibujo y pintura sobre cartón se analizaron intuitivamente y a través de una lectura poética con ojos sensibles. Parece que, desde el proceso de producción simbólica de los emojis hasta la confrontación del análisis con contribuciones teóricas, los contornos de la juventud no pueden definirse con homogeneidad y unicidad, mostrando la ausencia de una clasificación predefinida para la identidad juvenil. De esta manera, se abren otros caminos y conexiones para las interpretaciones del multi / plurisense de sus identidades individuales, así como de sus categorías. Aún así, es evidente, las influencias que surgen de los diferentes modos representativos en el ciberespacio en la producción de identidad fuera de él y viceversa, corroborando con las diversidades y diferencias en las formas de ser joven.

Palabras clave: Emojis. Cultura digital. Juventudes Identidades juveniles. Sociopoética

\section{Referências}

ADAD, S. J. H. C. A sociopoética e os cincos princípios: a filosofia dos corpos misturados na pesquisa em educação. In: ADAD, S. J. H. C. et al. (org.). Tudo que não inventamos é falso: dispositivos artísticos para pesquisar, ensinar e aprender com sociopoética. Fortaleza: EdUECE, 2014. p. 41-59.

ADAD, S. J. H. C. Corpos de rua: cartografia dos saberes juvenis e o sociopoetizar dos desejos dos educadores. Fortaleza: EdUFC, 2011.

ADAD, S. J. H. C.; GAMA, M. Os corpos-bichos dos estudantes como mecanismo de fuga às identidades fixas: uma oficina sociopoética. In: BOMFIM, M. do C. A. do; ADAD, S. J. H. C.; NASCIMENTO, A. L. do (org.). Educação, diversidades e politicas de inclusão: juventudes, cultura de paz e subjetividades. Teresina: EdUFPI, 2014. p. 157-169. v. 2.

BAUMAN, Z. 44 Cartas do mundo líquido moderno. Rio de Janeiro: Zahar, 2011.

BRITO, A. D. B. de. O discurso da afetividade e a linguagem dos emoctions. Revista Letra Magna, Cubatão, n. 9. p. 1-21, jul./dez. 2008. Disponível em: http://www.letramagna.com/emoticons.pdf. Acesso em: 5 jun. 2018.

CANEVACCI, M. Autorrepresentação: movimentar epistemologias no contexto da cultura digital e da metrópole comunicacional. Novos Olhares, [s. l.], v. 4, n. 1, p. 16-20, 2015. Disponível em: https://doi. org/10.11606/issn.2238-7714.no.2015.102237. Acesso em: 10 out. 2020. 
CANEVACCI, M. Comunicação entre corpos e metrópoles. Revista Signos do Consumo, São Paulo, v. 1, n. 1, p. 8-20, abr. 2009. Disponível em: https://doi.org/10.11606/issn.1984-5057.v1i1p8-20. Acesso em: 20 fev. 2018.

CASTRO, A. M. C. de. O corpo coletivo de barro como dispositivo de produção de confetos do educar para socioeducadores. In: ADAD, S. J. H. C. et al. (org.). Tudo que não inventamos é falso: dispositivos artísticos para pesquisar, ensinar e aprender com Sociopoética. Fortaleza: EdUECE, 2014. p. 19-39.

COSTA, D. P. da; VIEIRA, M. D. dos S. Visualizando cibercultura em rastros digitais juvenis no Instagram. Revista Interdisciplinar de Ciência Aplicada, Petrópolis, v. 4, n. 7, p. 17-23, jun. 2019. Disponível em: http://www.ucs.br/etc/revistas/index.php/ricaucs/article/ view/6714/3851. Acesso em: 10 out. 2020.

DAYRELL, J. O jovem como sujeito social. Revista Brasileira de Educação, Rio de Janeiro, n. 24, p. 44-52, dez. 2003. Disponível em: https://doi.org/10.1590/S1413-24782003000300004. Acesso em: 12 out. 2017.

GAUTHIER, J. A sociopoética como prática de pesquisa integral. Revista de Enfermagem UERJ, Rio de Janeiro, v. 22, n. 6, p. 848-52, nov./dez. 2014. Disponível em: http://dx.doi.org/10.12957/reuerj.2014.15781. Acesso em: 20 nov. 2017.

GAUTHIER, J. A questão da metáfora, da referência e do sentido em pesquisas qualitativas: o aporte da sociopoética. Revista Brasileira de Educação, Rio de Janeiro, n. 25, p. 127-142, abr. 2004. Disponível em: https://doi.org/10.1590/S1413-24782004000100012. Acesso em: 20 nov. 2017.

GAUTHIER, J. Sociopoética e formação do pesquisador integral. Revista Psicologia, Diversidade e Saúde, Bahia, v. 4, n. 1, p. 78-86, jul. 2015. Disponível em: http://dx.doi.org/10.17267/2317-3394rpds.v4i1.459. Acesso em: 20 nov. 2017.

MARTINS, L. R.; ADAD, S. J. H. C. A produção de subjetividade pelos(as) jovens da escola pública sobre o corpo estranho nas redes sociais: uma inspiração sociopoética. In: BOMFIM, M. do C. A. do; ADAD, S. J. H. C.; NASCIMENTO, A. L. do (org.). Educação, diversidades e politicas de inclusão: juventudes, cultura de paz e subjetividades. v. 2. Teresina: EdUFPI, 2014. p. 81-95.

MORO, G. H. M. Emoticons, emojis e ícones como modelo de comunicação e linguagem: relações culturais e tecnológicas. Revista de Estudos da Comunicação, Curitiba, v. 17, n. 43, p. 53-70, set./dez. 2016. Disponível em: http://www2.pucpr.br/reol/pb/index.php/comunicaca o?dd $1=16455 \&$ dd99 $=$ view\&dd98 = pb. Acesso em: 15 jan. 2018 .

PAIS, J. M. Jovens e cidadania. sociologia, problemas e práticas, Lisboa, v. 1, n. 49, p. 53-70, fev. 2005. 
PAIVA, V. L. M. de O. e. A linguagem dos emojis. Trabalhos em

Linguísticas Aplicadas, Campinas, v. 55, n. 2, p. 379-399, mai./ago. 2016. Disponível em: http://dx.doi.org/10.1590/010318134955176321. Acesso em: 5 jun. 2018.

PALFREY, J.; GASSER, U. Nascidos na era digital: entendendo a primeira geração de nativos digitais. Porto Alegre: Artmed, 2011.

PETIT, S. H. Sociopoética: potencializando a dimensão poética da pesquisa. In: ADAD, S. J. H. C. et al. (org.). Tudo que não inventamos é falso: dispositivos artísticos para pesquisar, ensinar e aprender com Sociopoética. Fortaleza: EdUECE, 2014. p. 19-39.

SANTOS, M. da C. de S. Páginas sociopoéticas: deslizando nas ideias e nos conceitos de jovens sobre leitura. 2013. Dissertação (Mestrado em Educação) - Universidade Federal do Piauí, Teresina, 2013. 